\title{
Widening educational disparities in all-cause mortality: An analysis of Austrian data with international comparisons
}

\author{
Franz Schwarz*
}

\begin{abstract}
Recent studies have demonstrated a widening in the relative mortality gap between the various socio-economic classes in several industrialised, Western countries. The present paper aims to determine whether or not education-related differentials in mortality have increased between 1981/82 and 1991/92 in Austria, and compares these findings with those gleaned from other European countries as well as the US and New Zealand. For the Austrian analysis, the data source consists of census records from 1981 and 1991 for the entire Austrian population that were linked with the respective death registry records for a follow-up period of one year. The disparities were measured by means of the regression-based Slope Index of Inequality and Relative Index of Inequality. The findings suggest that educational inequalities in mortality have widened in Austria, but more among men than among women. Austrian results are similar to patterns observed in other countries. International patterns pertaining to social disparities in mortality appeared mixed, when we distinguish between the various age groups and between men and women. However, widening educational mortality disparities are a worldwide phenomenon, a phenomenon that persists even when the educational expansion of the 1980s is taken into account.
\end{abstract}

\section{Introduction}

An inverse relationship has been well-documented between social class and mortality. Studies from various countries have persistently shown that those at the higher end of the social scale enjoy better health and live longer than those at the lower end (Huisman et al. 2004; Kitagawa and Hauser 1973; Kunst 1997; Spijker 2004; Whitehead and Diderichsen 1997). In Austria, socio-economic mortality inequalities have been reported for the years 1981/82 (Doblhammer 1997) and

\footnotetext{
* Franz Schwarz, Vienna Institute of Demography, Austrian Academy of Sciences, Vienna, Austria; E-mail: franz.schwarz@oeaw.ac.at
} 
1991/92 (Schwarz 2007) and 2001/02 (Klotz 2007). Doblhammer, Rau and Kytir (2005) recently reported a widening gap between 1981/82 and 1991/92 in educational and occupational differentials in all-cause mortality. The present paper reconsiders the changes in the educational differentials in mortality that occurred during the 1980s among people 30 to 74 years old, using a regressionbased measure of inequality, the Relative Index of Inequality. This measure has the big advantage of taking into account the relative position of different educational groups. Hence, it allows for comparisons of populations that differ in their educational distribution, and of populations whose distribution of education has changed over time. Changes in educational distribution may be partly responsible for the increased social inequity health gap, because a decreasing number of people with low education levels means that their relative position at the social scale worsens.

This study also assesses international trends in educational mortality inequalities, with regards to sex and age, and whether the Austrian trends differ from those reported internationally. Recent studies from several countries have documented a widening of the relative mortality gap between socio-economic groups. In the United States, for example, there were few differentials among whites in 1960 (Kitagawa and Hauser 1973); but data from the 1980s suggest the existence of substantial educational differentials in mortality (Feldman et al. 1989; Pappas et al. 1993; Preston and Elo 1995; Schalick et al. 2000). An EUsponsored project to monitor socio-economic inequalities in mortality and morbidity in Europe also produced evidence, from all monitored countries, of a widening of relative inequalities in mortality between the early 1980s and early 1990s (Kunst et al. 2004; Kunst, Bos and Mackenbach 2001; Mackenbach et al. 2003). Findings from individual European countries - the United Kingdom (Drever and Buntig 1997; Harding et al. 1997; Marang-van de Mheen et al. 1998; Pamuk 1985), Austria (Doblhammer et al. 2005), Finland (Martikainen, Valkonen and Martelin 2001; Valkonen 1999; Valkonen 2001; Valkonen, Martelin and Rimpela 1990; Valkonen et al. 1993), Denmark (Valkonen 2001), Norway (Dahl and Kjaersgaard 1993), Sweden (Valkonen 2001), Spain (Borrell et al. 1997; Regidor, Gutiérrez-Fisac and Rodriguez 1995) and Italy/Turin (Valkonen 2001) as well as recent studies conducted in Russia (Shkolnikov et al. 1998) and New Zealand (Blakely et al. 2005), all point to a widening of social class gradients in mortality over the past few decades. Furthermore, small-area-based socioeconomic mortality data from Australia suggest that the highest death rates occur in the most disadvantaged areas, with increases and decreases in the gap dependent upon sex and age (Turrell and Mathers 2001). This paper collects all existing results on educational mortality disparities and adds the Austrian ones for international comparison. 


\section{Data and Methods}

To obtain information on the socio-economic characteristics of the deceased, individual-level census records of the entire Austrian population, from 1981 and 1991, were linked with the death registry for a follow-up period of one year. In the death registry, 90,693 records in total were registered between 12 May 1981 (census day) and 13 May 1982, and 84,074 records between 15 May 1991 and 14 May 1992. For the period 1981/82, 88.4\% of the death records in Vienna were successfully linked to the census, while the number was between $91.3 \%$ and $94.2 \%$ in the other provinces; the linkage success for the period 1991/92 was $84.4 \%$ in Vienna and between $88.4 \%$ and $92.7 \%$ in the other provinces. Since the postal address was one of the key attributes to link the two datasets, linkage success was significantly influenced by peoples' mobility before death, which apparently is higher in Vienna. The record linkage approach and possible reasons for regionally-different linkage success rates is described in detail by Doblhammer et al. (2005). The final dataset includes the population aged 30-74 years old and contains, in total, 3,805,207 individual records for 1981/82 and $4,064,184$ for 1991/92. In these populations, 37,064 and 29,443 died within the one-year observation period, respectively.

For the assessment of mortality inequalities, the educational level was chosen as the indicator of social stratification, since it is available for all adults, whether or not they are currently in the labour force, and it remains virtually constant throughout adulthood. Furthermore, it is less influenced by health problems that develop during adulthood than indicators such as occupation or income (Davey Smith et al. 1998; Preston and Elo 1995). The levels of education used in this study are: Low (compulsory education); Middle (apprenticeship or vocational school); and High (secondary school diploma qualifying for university admission, college, university). Table 1 reveals the educational expansion that took place in the 1980 s, a time when the proportion of the population deemed to have higher education steadily increased. However, substantial discrepancies still exist in the educational distributions of men and women. Furthermore, despite classifying those with various levels of higher education into one category, the percentage of better-educated females remained very small, especially among the elderly in 1981/82.

Age-standardised death rates for each level of education and each sex were calculated based upon 5-year age groups, using the total population for 1991 as the standard population. Absolute and relative mortality inequalities between the educational groups were analysed by calculating the Slope Index of Inequality (SII) and its relative counterpart, the Relative Index of Inequality (RII). The basic concept of these measures was introduced by Preston, Haines and Pamuk in 1981 (cf. Pamuk 1985; Preston and Elo 1995). The SII is obtained by arranging the education groups from lowest to highest on a horizontal axis, and computing the cumulative proportionate distribution of the population. As a result, each group 
covers a range on the $x$-axis proportional to its population size, on a scale from 0 to 1 . Then, the age-standardised death rate of each education group is plotted against the midpoint of the percentile range of the respective education group. The SII is the regression slope $\beta$ of the relationship between the death rates and the cumulative educational midpoints.

Table 1:

Percentage of the population and deaths in each educational category, by sex and age group, Austria, 1981/82 and 1991/92

\begin{tabular}{|c|c|c|c|c|c|c|c|c|}
\hline \multirow[t]{3}{*}{ Education } & \multicolumn{4}{|c|}{ Males } & \multicolumn{4}{|c|}{ Females } \\
\hline & \multicolumn{2}{|c|}{ 30-59 years } & \multicolumn{2}{|c|}{$60-74$ years } & \multicolumn{2}{|c|}{ 30-59 years } & \multicolumn{2}{|c|}{$60-74$ years } \\
\hline & 1981/82 & $1991 / 92$ & 1981/82 & $1991 / 92$ & 1981/82 & $1991 / 92$ & 1981/82 & $1991 / 92$ \\
\hline \multicolumn{9}{|l|}{ Population } \\
\hline Low & 35.1 & 25.4 & 45.8 & 39.2 & 57.9 & 43.7 & 75.2 & 67.6 \\
\hline Middle & 51.1 & 56.9 & 42.1 & 46.6 & 33.8 & 43.0 & 20.1 & 25.4 \\
\hline High & 13.7 & 17.6 & 12.1 & 14.3 & 8.3 & 13.4 & 4.7 & 7.0 \\
\hline $\mathrm{N}$ & $1,367,950$ & $1,519,864$ & 387,957 & 426,571 & $1,440,704$ & $1,504,472$ & 608,596 & 613,277 \\
\hline \multicolumn{9}{|l|}{ Deaths } \\
\hline Low & 46.9 & 38.0 & 49.7 & 45.7 & 68.9 & 57.4 & 78.6 & 72.8 \\
\hline Middle & 45.5 & 53.9 & 41.8 & 44.3 & 25.4 & 35.0 & 18.3 & 22.2 \\
\hline High & 7.6 & 8.2 & 8.5 & 10.0 & 5.8 & 7.6 & 3.0 & 4.9 \\
\hline Deaths & 7,520 & 6,461 & 13,904 & 11,059 & 4,005 & 3,257 & 11,635 & 8,666 \\
\hline
\end{tabular}

The SII estimates, in absolute terms, how much of a decline in the death rates occurs from the $0^{\text {th }}$ to the $100^{\text {th }}$ percentile for education-which refer to the hypothetically lowest to highest educational level. Since mortality and education are inversely related in the vast majority of causes of death, a minus sign is placed in front of SII to obtain positive values for an inverse association. Hence, a positive value indicates that mortality decreases with increasing education; a negative SII means that mortality rises with increasing education.

The SII incorporates the concept of 'burden' by being sensitive to the level of mortality. The Relative Index of Inequality (RII), on the other hand, focuses entirely on the equity of the distribution of mortality - the level of mortality being taken out of the calculation. It is obtained by dividing the SII by the overall mean death rate for all educational levels combined. The RII indicates the mean proportionate decline in mortality when levels advance from lowest to highest. A detailed specification of the SII and RII, along with confidence intervals, can be found in Hayes and Berry (2002).

Kunst and Mackenbach (1994) used not only the regression slope $\beta$ to describe the relationship between death rates and midpoints in cumulative educational distribution, but also the constant $\alpha$ : $R I I_{K M}=\alpha /(\alpha+\beta)$. While the original RII lets us estimate the average degree of decline in death rates from the 0 th to the 100th percentile in education, $R I I_{K M}$ measures the mortality ratio of the hypothetically most disadvantaged (0th percentile) to the hypothetically most advantaged (100th percentile). 
There are, however, many measures of inequality that would fit the purposes of the present study (Mackenbach and Kunst 1997; Wagstaff, Paci and van Doorslaer 1991). This paper uses the SII and the RII for two reasons: (1) they allow very efficient comparisons of the disparities, because they include mortality levels for all three educational levels at once; (2) they take into account the relative position and size of the educational groups, which is especially useful when populations differ in their distribution with respect to the inequality variable, or when this distribution changes over time-which clearly is the case in the present study.

\section{Results}

As Table 2 shows, educational inequalities in mortality are evident for both age groups and sexes, and there was a relative decline in age-standardised death rates for each level of education from 1981/82 to 1991/92. However, even though, in relative terms, the decline in death rates turned out to be larger with increasing levels of education for both age groups and sexes, the data describing absolute declines in death rates are mixed. Among men 30-59 years old, for example, the absolute decline in death rates was highest among middle-educated men $(0.98$ deaths per 1,000 person-years) and lowest among highly educated working-age males ( 0.86 deaths per 1,000 person-years). In relative terms, however, mortality decreased most among the highest educated $(27.1 \%)$ and least for those with a low level of education (14.5\%). Among females 30-59 years old, the absolute changes in death rates were about the same for all levels of education; but, in relative terms, the decline in death rates also increased with increasing levels of education $(-12 \%$ to $-17.6 \%)$.

The absolute decline in death rate among older men was 4.99 deaths per 1,000 for those with the least education; whereas, among those with middle-level education, it was 6.55 deaths per 1,000 person-years. In relative terms, the declines were similar to those observed in the youngest age group. Among older females, differences in the absolute and relative declines in death rates have been minor; but here again the relative decline appears to rise slightly with an increasing level of education, from $-18.2 \%$ to $-22.2 \%$. 
Table 2

Age-standardised mortality rates and absolute and relative change from 1981/82 to 1991/92 in Austria, by education, sex and age group (95\% confidence intervals in parentheses)

\begin{tabular}{|c|c|c|c|c|c|c|c|}
\hline & \multicolumn{4}{|c|}{ Age-standardised death rates per 1,000} & \multicolumn{3}{|c|}{ Change from $1981 / 82$ to $1991 / 92$} \\
\hline & & 1981/82 & & 1991/92 & & Absolute & Relative in \% \\
\hline \multicolumn{8}{|c|}{ 30-59 years } \\
\hline \multicolumn{8}{|c|}{ Males } \\
\hline Low & 6.44 & $(6.23-6.66)$ & 5.51 & $(5.29-5.73)$ & -0.93 & $(-1.24-0.62)$ & $-14.5 \quad(-18.9-9.9)$ \\
\hline Middle & 5.13 & $(4.95-5.30)$ & 4.15 & $(4.01-4.29)$ & -0.98 & $(-1.20-0.76)$ & $-19.0 \quad(-22.8-15.1)$ \\
\hline High & 3.18 & $(2.92-3.44)$ & 2.32 & $(2.11-2.52)$ & -0.86 & $(-1.20-0.53)$ & $-27.1 \quad(-35.4-17.8)$ \\
\hline \multicolumn{8}{|l|}{ Females } \\
\hline Low & 2.78 & $(2.67-2.89)$ & 2.45 & $(2.33-2.56)$ & -0.33 & $(-0.49-0.18)$ & $-12.0 \quad(-17.2-6.5)$ \\
\hline Middle & 2.26 & $(2.12-2.40)$ & 1.96 & $(1.84-2.07)$ & -0.31 & $(-0.49-0.12)$ & $-13.6 \quad(-20.7-5.8)$ \\
\hline High & 2.06 & $(1.78-2.33)$ & 1.70 & $(1.47-1.92)$ & -0.36 & $(-0.72-0.01)$ & $-17.6 \quad(-31.7-0.4)$ \\
\hline \multicolumn{8}{|c|}{ 60-74 years } \\
\hline \multicolumn{8}{|l|}{ Males } \\
\hline Low & 35.28 & $(34.42-36.13)$ & 30.29 & $(29.46-31.11)$ & -4.99 & $(-6.18-3.80)$ & $-14.1 \quad(-17.2-11.0)$ \\
\hline Middle & 32.14 & $(31.29-32.99)$ & 25.59 & $(24.88-26.29)$ & -6.55 & $(-7.66-5.45)$ & $-20.4 \quad(-23.4-17.3)$ \\
\hline High & 24.01 & $(22.65-25.38)$ & 17.76 & $(16.72-18.80)$ & -6.25 & $(-7.97-4.53)$ & $-26.0 \quad(-31.8-19.7)$ \\
\hline \multicolumn{8}{|l|}{ Females } \\
\hline Low & 18.50 & $(18.12-18.89)$ & 15.14 & $(14.77-15.51)$ & -3.36 & $(-3.89-2.83)$ & $-18.2(-20.8-15.5)$ \\
\hline Middle & 16.45 & $(15.74-17.15)$ & 12.82 & $(12.25-13.39)$ & -3.63 & $(-4.54-2.72)$ & $-22.1 \quad(-26.7-17.1)$ \\
\hline High & 13.28 & $(11.90-14.66)$ & 10.34 & $(9.36-11.31)$ & -2.94 & $(-4.64-1.25)$ & $-22.2(-32.4-10.4)$ \\
\hline
\end{tabular}

Table 3:

Indices of inequality, Austria, 1981/82 and 1991/92 (95\% CI in parentheses)

\begin{tabular}{ccccc}
\hline Sex and age & $\begin{array}{c}\text { Rate difference } \\
\text { lowest vs. highest } \\
\text { educational level } \\
\text { (per 1,000) }\end{array}$ & $\begin{array}{c}\text { Rate ratio } \\
\text { lowest vs. highest } \\
\text { educational level }\end{array}$ & $\begin{array}{c}\text { Slope Index of } \\
\text { Inequality (SII) }\end{array}$ & $\begin{array}{c}\text { Relative Index of } \\
\text { Inequality } \\
\text { (RII) }\end{array}$ \\
\hline $\begin{array}{c}\mathbf{3 0 - 5 9} \text { years } \\
\text { Males }\end{array}$ & & & & \\
$\quad$ 1981/82 & $3.26(2.92-3.61)$ & $2.03(1.85-2.22)$ & $4.25(3.84-4.66)$ & $2.37(2.10-2.69)$ \\
$\quad$ 1991/92 & $3.19(2.89-3.49)$ & $2.38(2.16-2.62)$ & $4.06(3.71-4.40)$ & $2.96(2.59-3.37)$ \\
Females & & & & \\
$1981 / 82$ & $0.72(0.43-1.02)$ & $1.35(1.18-1.55)$ & $1.09(0.70-1.48)$ & $1.54(1.25-1.90)$ \\
$1991 / 92$ & $0.75(0.50-1.00)$ & $1.44(1.25-1.66)$ & $1.06(0.74-1.37)$ & $1.66(1.37-2.00)$ \\
$\mathbf{6 0 - 7 4}$ years & & & & \\
Males & & & & \\
$1981 / 82$ & $11.26(9.65-12.88)$ & $1.47(1.38-1.56)$ & $15.02(12.95-17.10)$ & $1.61(1.48-1.75)$ \\
$1991 / 92$ & $12.53(11.20-13.85)$ & $1.71(1.60-1.82)$ & $16.69(15.03-18.36)$ & $1.95(1.78-2.13)$ \\
Females & & & & \\
$1981 / 82$ & $5.22(3.79-6.66)$ & $1.39(1.25-1.55)$ & $7.47(5.41-9.53)$ & $1.53(1.29-1.82)$ \\
$1991 / 92$ & $4.80(3.76-5.85)$ & $1.46(1.33-1.62)$ & $7.07(5.58-8.56)$ & $1.66(1.41-1.96)$ \\
\hline
\end{tabular}


For women, the changes in educational inequalities in mortality were much smaller than for men, both in absolute and relative terms. Among younger females, there was no change in the SII, and just a slight increase in the RII, from 1.54 to 1.66. Among older females, the SII decreased from 7.47 to 4.07 deaths per 1,000 between the hypothetically least and most educated, while the RII rose slightly from 1.53 to 1.66 . The outcomes for the rate differences and rate ratios are similar to the SII and the RII.

Table 4 presents the RII for educational differentials in mortality in the early 1980s and in the 1990s in five European countries, in New Zealand and in the US. To reveal possible international variations in age-specific trends, a distinction was made between younger, middle-aged and older adults. Kunst et al. $(2004 ; 2001)$ expressed relative inequalities in mortality by means of the RII,

Table 4:

Relative Index of Inequality (RII) for educational mortality differentials, by age and sex

\begin{tabular}{|c|c|c|c|c|c|}
\hline \multirow[t]{2}{*}{ Country } & \multirow[t]{2}{*}{ Age } & \multicolumn{2}{|c|}{ Males } & \multicolumn{2}{|c|}{ Females } \\
\hline & & Early 1980 & $1990 s^{[d]}$ & Early 1980 & $1990 \mathrm{~s}^{[\mathrm{d}]}$ \\
\hline \multirow[t]{3}{*}{ Austria } & $30-44$ & $3.48(2.54-4.77)$ & $3.10(2.50-3.83)$ & $1.42(1.01-2.00)$ & $1.80(1.38-2.35)$ \\
\hline & & $1.80(1.61-2.02)$ & $2.55(2.23-2.92)$ & $1.56(1.24-1.96)$ & $1.61(1.28-2.02)$ \\
\hline & $60-74$ & $1.61(1.48-1.75)$ & $1.95(1.78-2.13)$ & $1.53(1.29-1.82)$ & $1.66(1.41-1.96)$ \\
\hline \multirow[t]{3}{*}{ Finland $^{[\mathrm{a}]}$} & $30-44$ & $2.87(2.63-3.14)$ & $3.36(3.11-3.64)$ & $2.13(1.84-2.48)$ & $3.29(2.89-3.75)$ \\
\hline & & $2.16(2.02$ & $2.22(2.09-2.36)$ & $1.63(1.47-1.80)$ & $1.92(1.75-2.10)$ \\
\hline & $60-74$ & $1.72(1.63-1.80)$ & $1.80(1.72-1.88)$ & $1.67(1.57-1.78)$ & $1.61(1.52-1.70)$ \\
\hline \multirow[t]{3}{*}{ Norway ${ }^{[a]}$} & $30-44$ & $3.16(2.79-3.59)$ & $3.85(3.42-4.35)$ & $1.46(1.23-1.73)$ & $2.45(2.08-2.90)$ \\
\hline & $45-59$ & $1.87(1.76-1.99)$ & $2.48(2.31-2.67)$ & $1.63(1.49-1.79)$ & $2.01(1.81-2.22)$ \\
\hline & $60-74$ & $1.43(1.38-1.49)$ & $1.70(1.63-1.77)$ & $1.49(1.42-1.57)$ & $1.78(1.69-1.88)$ \\
\hline \multirow[t]{2}{*}{ Denmark $^{[\mathrm{a}]}$} & $30-44$ & $1.98(1.77-2.20)$ & $2.86(2.58-3.16)$ & $1.50(1.31-1.71)$ & $2.04(1.79-2.34)$ \\
\hline & & $1.47(1.37-1.57)$ & $1.75(1.65-1.86)$ & $1.49(1.37-1.63)$ & $1.61(1.50-1.73)$ \\
\hline \multirow{3}{*}{$\begin{array}{l}\text { City of } \\
\text { Turin }^{[a]}\end{array}$} & $30-44$ & $1.92(1.50-2.46)$ & $3.02(2.28-4.02)$ & $1.05(0.78-1.42)$ & $1.62(1.11-2.37)$ \\
\hline & $45-59$ & $1.44(1.28-1.61)$ & $2.03(1.77-2.34)$ & $1.12(0.95-1.32)$ & $1.24(1.03-1.50)$ \\
\hline & & $1.35(1.24-1.46)$ & $1.43(1.32-1.56)$ & $1.45(1.29-1.61)$ & $1.36(1.22-1.53)$ \\
\hline \multirow{4}{*}{$\begin{array}{l}\text { New } \\
\text { Zealand }^{[b]}\end{array}$} & $25-44$ & $2.5 \quad(1.8-3.5)$ & $3.0 \quad(2.3-4.0)$ & $1.8 \quad(1.3-2.4)$ & $2.4 \quad(1.7-3.3)$ \\
\hline & $45-59$ & $1.7 \quad(1.4-2.0)$ & $2.3 \quad(2.0-2.6)$ & $1.7(1.3-2.2)$ & $1.9 \quad(1.6-2.2)$ \\
\hline & $60-77$ & $1.5 \quad(1.3-1.6)$ & $1.4(1.3-1.5)$ & $1.6(1.4-1.8)$ & $1.6 \quad(1.5-1.7)$ \\
\hline & & 1960 & 1979-85 & 1960 & $1979-85$ \\
\hline \multirow[t]{2}{*}{$\mathrm{USA}^{[\mathrm{c}]}$} & $25-64$ & 0.49 & 0.80 & 0.56 & 0.41 \\
\hline & $65-74$ & 0.13 & 0.54 & 0.44 & 0.55 \\
\hline
\end{tabular}

Notes and sources: [a] Source: Kunst et al. (2004; 2001)

[b] Source: Blakely et al. (2005)

[c] Source: Preston and Elo (1995); the presented measure is the Slope Index of Inequality divided by the overall mean death rate, which also called Relative Index of Inequality (cf. Methods Section); no confidence intervals available; white males and females only.

[d] Austria: 1991/92; Finland, Norway, Denmark, Turin: 1990-94; New Zealand: 1996-99 
which has the advantage of taking into account differences in educational distribution between age groups, in particular the fact that younger people tend to have higher levels of education. In the US, relative inequalities were measured using the original RII-which is the SII divided by the overall death rate-while the Kunst-Mackenbach RII was used in other countries.

Educational inequalities in mortality were evident in all countries, and differentials appeared to decline with increasing age more among men than among women. Young and middle-aged men were most affected by the widening educational disparities in mortality between the early 1980s and the 1990s. Austrian men aged 30-44 departed from this pattern, with a slight decrease in the RII over the 1980s. Finnish men aged 45-59 also departed from the general pattern, showing almost no change in their social inequity gap during the 1980s. Among older men, a notable widening of the gap occurred in Austria, Norway, Denmark and the US. For females, the gap tended to be wider among younger women than among middle-aged ones. Apart from the US, among females, the age group of 30-44 years was most affected by the widening of educational inequalities. Among older females, a notable widening of the gap only occurred in Norway, Denmark and the US. The RII presented in Table 4, however, exhibit considerable statistical variability, especially in the estimates provided for people aged 30-44.

\section{Discussion}

The current study confirms that an inverse relationship exists between education and mortality and shows that in Austria the relative gap in all-cause mortality widened between 1981/82 and 1991/91. Whereas, in relative terms, the declines in death rates over the 1980s turned out to be greater with increasing educational level, the absolute decline in the rates was almost equal for all levels. Males were more affected by the increased disparities than females. The slight decrease in the mortality gap among Austrian men aged 30-44 is rather surprising and may have been the result of statistical variation.

The patterns of increasing disparities in mortality vary between countries, when we distinguish between age groups and between men and women; but the general trend points towards increasing relative inequalities worldwide. In Austria, the patterns are similar to those that have been reported in other European countries, the US and New Zealand. However, in the Nordic European countries, working-age females appear to be more affected by the widening gap; and in Finland, Turin and New Zealand, older males seem to be hardly affected at all by the broadening gap. The rapidly increasing disparities in mortality among females aged 30-44 were probably the result of educational expansion and the growth of equal opportunities for males and females. As a result, working females and men may now have many similar health and lifestyle parameters. 
Feldman et al. (1989) and Valkonen (2001) suggest that trends in social differentials for heart-disease mortality have been responsible for a sizeable proportion of the trends pertaining to all-cause mortality that exist in several European countries and in the US. The upper socio-economic groups apparently have benefited more from the decline in cardiovascular mortality. Other increased social inequalities in diseases also may be responsible for the widening social gap in mortality. For instance, lung-cancer mortality contributed to the increase in the gap in Norway and England (Valkonen 2001). However, Valkonen (2001), based upon results from his comparative European study, suggests that the contribution of causes is not systematic and that one should not generalise.

The single most responsible factor for the trend in cause-specific mortality may be divergence in health-related behaviour. Feldman et al. (1989) assume that people of higher socio-economic status may have adopted healthy lifestyles more rapidly. Valkonen (2001) suggests that the upper socio-economic groups have benefited more from the trend towards declining cardiovascular disease mortality, because they may have more quickly adopted the recommended health behaviours with respect to diet, smoking and physical activities, and they may also have had better access to new medical treatments. Probably the lower social classes ultimately will then benefit from modern medical treatments just like the higher classes when these treatments become more widely available and part of standard practice. As a result, the gap in mortality may decline in the future.

In Austria, smoking prevalence increased between 1986 and 1995, by 33.7\% among females and by $9.6 \%$ among males. Indicators of smoking among females (prevalence and cigarettes per day) are approaching those of males (Haidinger, Waldhort and Vutuc 1998). It is likely that those who are less educated represent a disproportionate segment of this increase. An upcoming study will examine educational disparities in health behaviour over the last three decades, to identify possible explanations for these widening disparities.

Changes in relative positions between educational groups may be partly responsible for the increased gap as well. For instance, a declining percentage of people with lower-level education means that their relative position on the social scale weakens. As a result, they may become an even more disadvantaged group. Using the regression-based Relative Index of Inequality allows for the relative position of the various educational groups to be taken into account.

Equal access to national health-care systems may improve health among the disadvantaged. However, Pamuk (1985) demonstrated that, in England, social inequalities in mortality have been increasing despite the introduction of a National Health Service in 1948. Likewise, the US Social Security Act that established Medicare and Medicaid in the US in 1965 could not prevent increasing social disparities in mortality, either (Feldman et al. 1989). In Austria, virtually everyone has a basic right to utilise the facilities made available by the Austrian health system. This means that everybody is entitled to preventative examinations, medical treatment, free medicine, dental treatment, nursing care at 
home or as an in-patient, payment of ambulance costs, etc. Regardless of these positive health-care conditions, the differentials have increased. It is likely, though, that these disparities would have been much larger without a public health-care system.

The significantly lower mortality levels observed among the higher educated imply that mortality can potentially be lessened among disadvantaged groups. Socio-economic inequalities are therefore a major public-health issue. Any decline in the disproportionately high mortality rates and disease prevalence rates among the disadvantaged could elevate the average health of a population significantly. The increase in relative socio-economic mortality disparities indicates greater social inequalities in general. Thus, efforts should be taken to improve the life circumstances of the disadvantaged in our society.

One fundamental response would be to concentrate on education. Education is a good indicator of social class (Davey Smith et al. 1998; Preston and Elo 1995) and a strong predictor of health behaviour and health. Nevertheless, Spielauer et al. (2004) have shown that, in Austria, a person's education is strongly associated with that of his or her parents. This suggests that a free and equally-accessible educational system does not necessarily guarantee equal opportunities for academic or career success. Any major focus on education would place tremendous levels of responsibility upon school teachers, and must start very early in a child's life, e.g., from the pre-school level.

Providing people with truly equal educational opportunities very likely does increase the average health status and life expectancy of a population; but it may not affect the magnitude of social disparities. Regardless of political and societal efforts, there still will be disadvantaged people with lower levels of education in our society, who are hardly amenable to intervention with regards to health behaviour. Moreover, children may adopt the poor health behaviour of their parents irrespective of their schooling. For example, in Austria it has been shown that the prevalence of overweight children is inversely correlated with parental education level, and the percentage of children who are not vaccinated increases significantly with decreasing parents' education (Schwarz 2003). Thus, parents must be made aware of the consequences of their own unhealthy lifestyles for their children; and efforts to promote a healthy lifestyle must begin at a very young age, before the unhealthy habits of parents are adopted, if any society wants to successfully eradicate or minimise social disparities in health and mortality. 


\section{Acknowledgements}

I would like to thank Alexia Fürnkranz-Prskawetz, Henriette Engelhardt and Elsie Pamuk for their support, suggestions and comments. Many thanks go to Alexander Hanika for support with data processing at Statistics Austria; without data access at Statistics Austria, this paper would not have been possible. I would like to thank Gabriele Doblhammer and Roland Rau, who initially merged data from the 1981 and 1991 Austrian census, respectively, with the death registry. I also would like to thank the anonymous reviewers for providing comments and suggestions that have helped to improve this paper.

\section{References}

Blakely, T., J. Fawcett, J. Atkinson, M. Tobias, and J. Cheung. 2005. "Decades of Disparity II: Socioeconomic mortality trends in New Zealand, 1981-1999.” In: Public Health Intelligence Occasional Bulletin 25. New Zealand: Ministry of Health.

Borrell, C., A. Plasencia, I. Pasarin, and V. Ortun. 1997. "Widening social inequalities in mortality: the case of Barcelona, a southern European city." Journal of Epidemiology and Community Health 51:659-667.

Dahl, E.and P. Kjaersgaard. 1993. "Trends in socioeconomic mortality differentials in post-war Norway: evidence and interpretations." Sociology of Health and Illness 15(5):587-611.

Davey Smith, G., C. Hart, D. Hole, P. MacKinnon, C. Gillis, G. Watt, D. Blane, and V. Hawthorne. 1998. "Education and occupational social class: which is the more important indicator of mortality risk?" Journal of Epidemiology and Community Health 52:153-190.

Doblhammer, G. 1997. "Socioeconomic differentials in Austrian adult mortality. A study based on linked census and death records for the years 1981/82." PhD Thesis, Institut für Statistik, University of Vienna.

Doblhammer, G., R. Rau, and J. Kytir. 2005. "Trends in educational and occupational differentials in all-cause mortality in Austria between 1981/82 and 1991/92." Wiener Klinische Wochenschrift 117(13-14):468-479.

Drever, F.and J. Buntig. 1997. "Patterns and trends in male mortality." In: Health Inequalities. Decennial Supplement, Series DS No. 15, edited by F. Drever and M. Whitehead. London: Office for National Statistics, pp. 95-107.

Feldman, J. J., D. M. Makuc, J. C. Kleinman, and J. Cornoni-Huntley. 1989. "National trends in educational differentials in mortality." American Journal of Epidemiology 129(5):919-933.

Haidinger, G., T. Waldhort, and C. Vutuc. 1998. "The prevalence of smoking in Austria." Preventive Medicine 27(1):50-55.

Harding, S., A. Bethune, R. Maxwell, and J. Brown. 1997. "Mortality trends using the Longitudinal Study." In: Health Inequalities. Decennial supplements, Series DS No. 15, edited by F. Drever and M. Whitehead. London: Office for National Statistics, pp. $143-155$ 
Hayes, L. J. and G. Berry. 2002. "Sampling variability of the Kunst-Mackenbach relative index if inequality." Journal of Epidemiology and Community Health 56:762-765.

Huisman, M., A. E. Kunst, O. Andersen, M. Bopp, J.-K. Borgan, C. Borrell, G. Costa, P. Deboosere, G. Desplanques, A. Donkin, S. Gadeyne, C. Minder, E. Regidor, T. Spadea, T. Valkonen, and J.P. Mackenbach. 2004. "Socioeconomic inequalities in mortality among elderly people in 11 European populations." Journal of Epidemiology and Community Health 58:468-475.

Kitagawa, E. M.and P. M. Hauser. 1973. Differential Mortality in the United States. A Study in Socioeconomic Epidemiology. Cambridge: Harvard University Press.

Klotz, J. 2007. "Soziale Unterschiede in der Sterblichkeit; Bildungsspezifische Sterbetafeln 2001/2002". Statistische Nachrichten; April 2007. Wien: Statistik Austria.

Kunst, A. E. 1997. "Cross-national comparisons of socio-economic differences in mortality." PhD Thesis, Erasmus University Rotterdam.

Kunst, A. E., V. Bos, O. Andersen, M. Cardano, G. Costa, and S. Harding. 2004. "Monitoring of trends in socioeconomic inequalities in mortality: Experiences from a European project." Demographic Research S2(9):232-254.

Kunst, A. E., V. Bos, and J.P. Mackenbach. 2001. "Monitoring socio-economic inequalities in health in the European Union: guidelines and illustrations. A report for the Health Monitoring Program of the European Commission." Rotterdam: Department of Public Health, Erasmus University Rotterdam.

Kunst, A. E. and J. P. Mackenbach. 1994. "Measuring Socioeconomic Inequalities in Health.” Copenhagen: WHO Regional Office for Europe.

Mackenbach, J. P., V. Bos, O. Andersen, M. Cardano, G. Costa, S. Harding, A. Reid, O. Hemstrom, T. Valkonen, and A.E. Kunst. 2003. "Widening socioeconomic inequalities in mortality in six Western European countries." International Journal of Epidemiology 32:830-837.

Mackenbach, J. P. and A.E. Kunst. 1997. "Measuring the magnitude of socio-economic inequalities in health: an overview of available measures illustrated with two examples from Europe." Social Science and Medicine 44(6):757-771.

Marang-van de Mheen, P. J., G. Davey Smith, C. L. Hart, and L. J. Gunning-Shepers. 1998. "Socioeconomic differentials among men within Great Britain: time trends and contributory causes." Journal of Epidemiology and Community Health 52:214-218.

Martikainen, P., T. Valkonen, and T. Martelin. 2001. "Change in male and female life expectancy by social class: decomposition by age and cause of death in Finland 197195." Journal of Epidemiology and Community Health(55):494-499.

Pamuk, E.R. 1985. "Social Class Inequality in Mortality from 1921 to 1972 in England and Wales." Population Studies 39:17-31.

Pappas, G., S. Queen, W. Hadden, and G. Fisher. 1993. "The increasing disparity in mortality between socioeconomic groups in the United States, 1960 and 1986." The New England Journal of Medicine 329(2):103-109.

Preston, S. H. and I. T. Elo. 1995. "Are Educational Differentials in Adult Mortality Increasing in the United States." Journal of Aging and Health 7(4):476-496.

Regidor, E., J. L. Gutiérrez-Fisac, and C. Rodriguez. 1995. "Increased socioeconomic differences in mortality in eight Spanish provinces." Social Science and Medicine 41:801-807. 
Schalick, L.M., W.C. Hadden, E. Pamuk, V. Navarro, and G. Pappas. 2000. "The Widening Gap in Death Rates among Income Groups in the United States from 19671986." International Journal of Health Services 30(1):13-26.

Schwarz, F. 2003. "Socioeconomic Inequalities in Health Behavior in Austria." In: OIF Working Paper 32-2003. Vienna: Institute for Family Studies.

Schwarz, F. 2007. "Causes of death contributing to educational mortality disparities in Austria." Wiener Klinische Wochenschrift 119(9-10): 309-317.

Shkolnikov, V., D.A. Leon, S. Adamets, E. Andreev, and A. Deev. 1998. "Educational level and adult mortality in Russia : an analysis of routine data 1979 to 1994." Social Science \& Medicine 47:357-369.

Spielauer, M., F. Schwarz, K. Städtner, and K. Schmid. 2004. "Education and Family. Intergenerational educational transmission within families and the influence of education on partner choice and fertility." In: Schriftenreihe des ÖIF Nr. 11 Vienna: Austrian Institute for Family Studies.

Spijker, J. 2004. Socioeconomic Determinants of Regional Mortality Differences in Europe. Amsterdam: Dutch University Press.

Turrell, G.and C. Mathers. 2001. "Socioeconomic inequalities in all-cause and specificcause mortality in Australia: 1985-1987 and 1995-1997." International Journal of Epidemiology 30(2):231-239.

Valkonen, T. 1999. "The widening differentials in adult mortality by socioeconomic status and their causes." In: Health and Mortality. Issues of Global Concern. Leuven.

Valkonen, T. 2001. "Trends in differential mortality in European countries." In: Trends in mortality and differential mortality, edited by J. Valin, F. Meslé, and T. Valkonen. Strasbourg: Council of Europe Publishing.

Valkonen, T., T. Martelin, and A. Rimpela. 1990. "Socio-economic Mortality Differences in Finland 1971-85." Helsinki: Statistics Finland.

Valkonen, T., T. Martelin, A. Rimpela, V. Notkola, and S. Savela. 1993. "Socio-economic Mortality Differences in Finland 1981-90.” In: Statistics Finland Population. Helsinki: Statistics Finland.

Wagstaff, A., P. Paci, and E. van Doorslaer. 1991. "On the measurement of inequalities in health." Social Science and Medicine 33:545-557.

Whitehead, M. and F. Diderichsen. 1997. "International evidence on social inequalities in health." In: Health Inequalities. Decennial Supplement, Series DS No. 15, edited by F. Drever and M. Whitehead. London: Office for National Statistics, pp. 44-68. 